\title{
Modelo de Rede Social Virtual para Inclusão Digital e Social
}

\author{
Yuri Fernando Simões Arce - \\ Universidade Cruzeiro do Sul - yuri.m.g74@gmail.com \\ Fabio Nunes Cerqueira - \\ Universidade Cruzeiro do Sul - f.nunes05@outlook.com \\ Hugo Dutra Profirio de Souza - Universidade Cruzeiro \\ do Sul - hugodutra12@gmail.com Juliano Schimiguel - \\ Universidade Cruzeiro do Sul - schimiguel@gmail.com \\ Célia Regina da Silva Rocha - Universidade Cruzeiro \\ do Sul - crsrocha@gmail.com
}

\begin{abstract}
Resumo. O rápido avanço da tecnologia na sociedade não só proporciona o auxílio de diversas ferramentas para comunicação e inclusão social, como também cria maior necessidade de presença na mesma, um grande exemplo disso são as redes sociais virtuais que se tornaram parte da rotina de grande parcela da população. Neste contexto, tivemos como objetivo encontrar e apresentar um modelo com interface e usabilidade de forma mais clara, permitindo assim que pessoas com deficiência intelectual se incluam em meios sociais digitais. A metodologia constou da análise das dificuldades, testando a usabilidade de outras redes sociais e posteriormente, a iteração com um modelo de rede social acessível gerada do estudo com um grupo de jovens e adultos deficientes intelectuais, frequentadores de um programa de educação especial. Este estudo, por fim, fornece resultados que comprovam a eficácia de uma interface mais adequada para uso daqueles que não estão acostumados com a quantidade excessiva de informação presente em diversos meios de comunicação hoje em dia.
\end{abstract}

Palavras chave: Deficiência Intelectual. Inclusão Social. Rede Social. TICs.

\begin{abstract}
The fast advancement of technology in society not only provides the aid of several tools for communication and social inclusion, but also creates a greater need to be present in it, a great example of this is the virtual social networks that have become part of the routine of a large part of the population, in this context we aimed to find ways to present a model with interface and usability in a clearer way, thus allowing that people with intellectual disability to be included in digital social media. The methodology consisted of the analysis of the difficulties, testing the usability of other social networks and later iteration with an accessible social network model generated from the study with a group of young and adults with intellectual disability, attending a special education program. This study finally provides results that prove the effectiveness of an interface more suitable for use by those who are not accustomed to the excessive amount of information present in various media nowadays.
\end{abstract}

Keywords: ICT. Intellectual Disability. Social Inclusion. Social Network.

\section{Introdução}

A Deficiência Intelectual (DI), segundo a Associação Americana sobre Deficiência Intelectual do Desenvolvimento (AAIDD), caracteriza-se por um funcionamento intelectual inferior à média (QI), associado a limitações adaptativas em pelo menos duas áreas de habilidades (comunicação, autocuidado, vida no lar, adaptação social, saúde e segurança, uso de recursos da comunidade, determinação, funções acadêmicas, lazer e trabalho), que ocorrem antes dos 18 anos de idade. 
No dia a dia, isso significa que boa parte das pessoas com DI tem dificuldade para aprender, entender e realizar atividades comuns para o restante da população. Em muitos momentos, os indivíduos com estas características apresentam comportamento que difere, em sua grande maioria, do comportamento considerado normal pela sociedade para a idade dos mesmos. (Adaptado de APAE-SP).

Dados divulgados pela Organização Mundial de Saúde (OMS) apontam que cerca de 5\% da população mundial têm alguma DI, o que torna importante nos dias atuais adotarmos táticas de inclusão tanto no mercado de trabalho quanto nas instituições de ensino. As pessoas com deficiência intelectual lutam para conseguir o primeiro emprego e, principalmente, para garantir que os seus direitos sejam respeitados, muitos destes também com debilidade física, encontram-se neste cenário fazendo com que projetos de inclusão sejam fundamentais.

Visto isso, é cada vez mais necessária na sociedade atual, a adaptação das estratégias e metodologias de inclusão para deficientes intelectuais, aliados a atualização da didática dos educadores contemporâneos, para propor novas alternativas que consigam auxiliar da melhor forma os deficientes.

As Tecnologias de Informação e Comunicação (TICs) englobam uma série de recursos tecnológicos que transformaram a maneira de nos comunicarmos, hoje, estamos cada vez mais imersos nelas, utilizando-as durante boa parte do dia, como por exemplo a internet, recurso que tornou-se indispensável na vida de uma grande parte da população.

Seguindo nesta linha de raciocínio, a tecnologia pode ser utilizada como recurso para inclusão social, desenvolvimento e construção de conhecimento. Segundo Ferreira (2010) e Vianna (2006), as tecnologias são adaptativas, possuem a capacidade de serem utilizadas como potencializadores das habilidades cognitivas e utilizá-las num contexto de mediação é a forma mais apropriada de garantir uma aprendizagem significativa em qualquer ambiente.

Dentre as inúmeras tecnologias modernas, utilizar redes sociais como um método de aliar conteúdo e interação social entre os alunos é possível, desde que intermediada da maneira certa, podem tanto trazer maior interesse ao assunto estudado quanto ajudar nas relações entre participantes de uma sala de aula.

O problema nestas tecnologias está no fato de que, do mesmo modo que podem auxiliar no aprendizado em sala de aula e promover a inclusão social, acabam por excluir as pessoas que não tem familiaridade com as mesmas, pois a maioria das grandes redes sociais não possuem conceitos de acessibilidade em suas interfaces.

Partindo destas informações e realizando um estudo com alunos frequentadores do Programa de Educação Especial - PROESP da Universidade Cruzeiro do Sul, percebemos que pessoas com Deficiência Intelectual enfrentam dificuldades tanto para se incluir coletivamente, quanto para utilizar as tecnologias atuais. Para auxiliar essa integração com o meio social e com as TICs, concluímos que o conceito de rede social virtual com acessibilidade seria uma boa maneira de promover inclusão social e digital para estes alunos.

Diante de tudo que foi exposto acima, este artigo tem como objetivo demonstrar um modelo, mais próximo do ideal possível, de rede social inclusiva criada a partir do estudo com DI, que não é necessariamente exclusiva para esse público, já que o projeto visa integrar os mesmos com um dos métodos de comunicação mais utilizados na atualidade, a internet. Para isso, iremos apresentar neste trabalho conceitos e teorias que 
são importantes para a inclusão social, inclusão digital e que serão a base do nosso modelo, analisando as teorias e autores que estudaram sobre as mesmas e mostrando como os resultados gerados podem ser benéficos.

\section{Referencial Teórico}

O termo TICs teve início em meados da década de 70, sendo atualizado constantemente conforme o tempo para abranger as novas utilidades das tecnologias, segundo a Unesco, estas são apenas uma parte de um contínuo desenvolvimento de tecnologias, onde todos podem apoiar e enriquecer a aprendizagem. Algumas de suas maiores características são a agilidade e a possibilidade de manipulação das informações mediante ao crescente apoio para conversação e transferência de dados entre as mesmas. Essa nova dinâmica das relações entre as pessoas e tecnologias foi desenhando o que hoje gera conceitos como a web semântica, Sociedade da Informação e do Conhecimento, dentre outras.

Alguns exemplos de TICs incluem: Computadores pessoais; Câmeras de vídeo e foto para computador ou Webcams; Suportes para guardar e portar dados como discos rígidos ou HDs, cartões de memória, pendrives, celulares, smartphones, televisões smart, tablets, mídias sociais, mobile learning, entre outros.

"As TIC são dinamizadoras da construção de conhecimentos;
permitem o desenvolvimento de práticas cidadãs; contribuem para o
surgimento do sentimento de pertença, diminuindo a violência;
promovem o engajamento e o trabalho colaborativo em torno de um
objetivo comum; permitem gerenciar com autonomia o tempo dos
estudos e com maior eficácia o processo de avaliação, diminuindo o
tempo gasto nessas tarefas. A conectividade com a Internet cria redes
virtuais de aprendizagem, que modificam as formas do ensinar e
aprender. (Tavares, 2014, p. 12)."

A evolução das TICs ao longo dos últimos anos, principalmente após a popularização da internet na sociedade, nos proporcionou uma nova maneira de interagirmos: através de redes sociais virtuais.

O conceito de redes data de antes da internet se popularizar, segundo Marteleto (2001) redes são:

"[...] ]sistema de nodos e elos; uma estrutura sem fronteiras; uma comunidade não geográfica, um sistema de apoio ou um sistema físico que se pareça com uma árvore ou uma rede. (Marteleto, 2001, p.72)"

Marteleto (2001) ainda diz que rede social pode ser definida como um conjunto de participantes autônomos, unindo ideias e recursos em torno de valores e interesses compartilhados, definição que demonstra como o modelo descrito poderia auxiliar a interação social entre os participantes desta.

Segundo Recuero (2010, p.9), as redes sociais funcionam com a prioridade fundamental da interação social, ou seja, busca conectar pessoas e proporcionar sua comunicação, portanto, podendo ser usufruída para forjar laços sociais. Estes laços são considerados um de nossos principais objetivos, criar um modelo que auxilie os deficientes a inserir-se socialmente por meio de uma rede social.

Além de serem poderosas ferramentas de capacitação presentes em nossas vidas, as TICs e as redes sociais têm o potencial de promover inclusão social na vida de certa parte da população. Segundo Oliveira (2004), inclusão social é um convidar a que se 
aproximem aqueles que estiveram historicamente excluídos ou deixado de lado.

Conforme dito por Andrade, Ferraci, Morgado (2016) e reafirmado por Orth, Mangan, Sarmento (2011) a democratização do acesso à tecnologia é uma forma de combater a exclusão digital e social. Em contrapartida, o mundo, conforme acontece nos dias atuais, baseado cada vez mais na tecnologia e na aprendizagem para um grupo seleto pode afastar da sociedade aqueles que não possuem este conhecimento. Da mesma forma que as TICs integram aqueles que possuem habilidades para operá-las, estas excluem os indivíduos que de alguma forma não tem acesso a essa tecnologia, um bom exemplo são pessoas com necessidades especiais e idosos que historicamente são excluídas desses processos.

Nesse contexto, a tecnologia precisa ser adaptada para a inclusão destes grupos que possuem dificuldades, como por exemplo, os softwares de leitura que auxiliam cegos a mexerem em um computador ou o aumento da fonte de páginas web para que idosos com idade mais avançada tenham menores problemas para leitura destes sites.

Para que essas adaptações tenham efeito na Internet é necessário que as páginas tenham acessibilidade. Segundo a W3C, criadora da Cartilha da Acessibilidade WEB, principal artigo sobre o assunto, o site para ser acessível deve ser: perceptível (informações de forma clara na tela), operável (fáceis de manusear), compreensível (conteúdo deve ser de fácil entendimento) e robusto (deve ter a capacidade de suportar todo tipo de usuários).

Atualmente utilizamos as redes sociais para quase tudo em nossas vidas, estamos conectados boa parte do tempo nestas redes, porém, estas dificilmente seguem os padrões descritos pela W3C, o Facebook, para utilizar uma rede amplamente utilizada pela população, contém uma série de informações na sua página principal, denominado feed de notícias e este comete relevantes erros na questão da acessibilidade para os deficientes intelectuais. Com a quantidade de informações presentes na tela ao mesmo tempo, e anúncios em algumas partes, o deficiente pode ter uma grande dificuldade para navegar em seu feed, pois a grande quantidade de elementos nas laterais acaba por tirar a atenção deles do foco principal da página.

Como trabalhos que demonstram conceitos que desejamos ter em nosso projeto, podemos ver portais que atendem as características de acessibilidade descritas acima como o site Acesso para todos ou o TodosNós da UNICAMP que para auxiliar a navegação contém opções para mudança de contraste das cores do site, aumento e diminuição do tamanho da fonte e utilização de teclas de acesso, onde por meio de atalhos no teclado é possível navegar dentre as páginas do site. É importante ressaltar que nosso modelo visa não utilizar o conceito de várias páginas, logo excluindo a necessidade da navegação pelo site por meio de atalhos.

\section{Metodologia}

Como provado por outros autores, as TICs são geradoras de conteúdos e benéficas se usadas de forma correta, aliando este conhecimento com a vontade dos deficientes intelectuais de se expressarem, uma rede social que reúne como fundamento esses aspectos de forma acessível se prova, dedutivamente, uma solução.

As grandes redes sociais de hoje, apesar dos esforços para deixar suas ferramentas mais acessíveis, já que elas estão crescendo tanto em sua complexidade, quanto no número de funções, apesar do desejo de muitos desses DIs de estarem inclusos através da TICs, o mesmo se torna difícil sem um aprendizado extensivo. 
Partindo destas informações, decidimos fazer um levantamentos das principais dificuldades de deficientes no Facebook, com objetivo de estudar formas de criar um modelo que beneficie os mesmos e posteriormente melhorá-lo com a prototipagem.

Para o levantamento dos dados de análise foram ministradas sessões em um dos laboratórios de informática, da Universidade Cruzeiro do Sul, no campus São Miguel durante cerca de 4 meses com 7 alunos, frequentadores do Programa de Educação Especial - PROESP, com faixa etária entre 17 e 48 anos, sendo a turma de maioria analfabeta, com 2 semialfabetizados e 1 alfabetizado, em um dos laboratórios de informática, da Universidade Cruzeiro do Sul, no campus São Miguel.

Os testes com os alunos procederam de forma a manter o mínimo de intervenção por parte dos avaliadores no uso da rede social, mas respondendo todas as dúvidas que pudessem surgir, analisando as adversidades encontradas no uso e anotando-as para o desenvolvimento do modelo. As sessões inicialmente foram feitas uma vez por semana durante duas horas.

Para avaliações preliminares sobre os principais problemas apontados pelos alunos, foram ministradas 6 aulas para utilização da rede social escolhida para teste. É necessário salientar que durante as aulas, a utilização da internet nos computadores do laboratório só pôde ser feita em uma máquina, um aluno por vez, devido a dificuldades relacionadas ao controle de conteúdo da instituição.

Para que os testes partissem todos do mesmo ponto, durante as sessões foram criadas credenciais novas para todos alunos, para conseguir uma visão mais ampla do processo de navegação como um todo.

Também para tentar demonstrar de maneira mais fiel o modelo, começamos a desenvolver um esboço prático do tema, inicialmente testado em servidores locais, utilizando como base HTML, CSS e Javascript, com a utilização do Bootstrap, uma biblioteca que reúne uma série de códigos pré-definido, com o objetivo de deixar o processo mais fácil e ágil. Para a escrita do código será usado o Brackets, uma IDE criada para desenvolvimento web.

\section{Estudo de caso}

Inicialmente foi explicado a ideia de redes sociais virtuais para os estudante, sendo que 3 deles já tinham conhecimento prévio sobre o conceito apresentado.

Após a explicação, foi solicitado que, um de cada vez tentasse criar suas credenciais na rede social escolhida para testes, e para que essa ação fosse possível era necessário primeiramente a criação de um e-mail, nesta parte, nenhum dos 7 avaliados conseguiram sem intervenções do monitor realizar a tarefa solicitada no prazo da aula, por este motivo, foi necessária a ajuda e um e-mail foi criado para cada um deles.

O próximo passo, similar ao primeiro, necessitou da criação de credenciais no Facebook, o mesmo também foi concluído com o auxílio dos avaliadores. Em seguida, foi explicado a eles o funcionamento do site, demonstrando a interface e suas funções, logo após foi disponibilizado um período de tempo para que cada um tentasse realizar o que desejassem, ressaltando novamente que infelizmente não usaram por muito tempo a limitação de tempo e por apenas uma máquina conseguir acesso a rede social que serviu de teste. Depois de 2 a 3 utilizações, cada uma com tempo médio de 40 minutos, a maioria deles apresentaram baixo desempenho na análise, necessitando de auxílio constante para execução das tarefas com exceção de um aluno, pelo fato dele ter maior conhecimento prévio de como era utilizar o Facebook, mas ainda sim este precisou de 
certo auxílio. A função que os alunos mais desejavam utilizar era a do Messenger, serviço de mensagens instantâneas presentes dentro da plataforma disponível de maneira integrada ao site, apenas na versão web. Focando apenas no que eles mais gostariam de acessar, foram instruídos novamente sobre como utilizar a rede.

Para conseguir utilizar o Messenger, é necessário passar por alguns passos que envolvem encontrar a pessoa desejada e o mesmo aceitar a solicitação de amizade e após isso, seguir uma determinada quantidade de etapas para que fosse visualizado a área do chat. Nenhum dos deles conseguiu seguir as duas etapas sozinhos, os avaliadores então realizaram as etapas citadas e deixaram que cada um enviasse algo ao colega. Todos os participantes gostaram da experiência, ficaram fascinados com as interações mas, mesmo com a empolgação, a curto e médio prazo não foi possível a eles realizar novamente as tarefas explicadas na semana seguinte, mas não é descartado a possibilidade de que com repetição e ensino seja possível o uso da função.

\subsection{Descrição de interface da rede social virtual}

Baseado nos dados coletados a partir das interações dos alunos com a rede social Facebook, foram levantadas e enumeradas as principais dificuldades de utilização, alguns pontos para servir como alicerce do trabalho, chegando assim a um modelo como base. É importante notar que a descrição a seguir não contará com todas as características do modelo, apenas as essenciais para o entendimento dos testes feitos.

Para desenvolver este conceito inclusivo utilizamos como base as seguintes dificuldades dos alunos:

- Dificuldades para o login.

- Problemas para assimilar o conceito de múltiplas guias no navegador e de "voltar a página".

- Encontrar funções como troca de mensagens(chat) ou publicação de fotos.

- Trocar imagem de perfil na rede social.

- Navegar em uma interface cheia de links e anúncios.
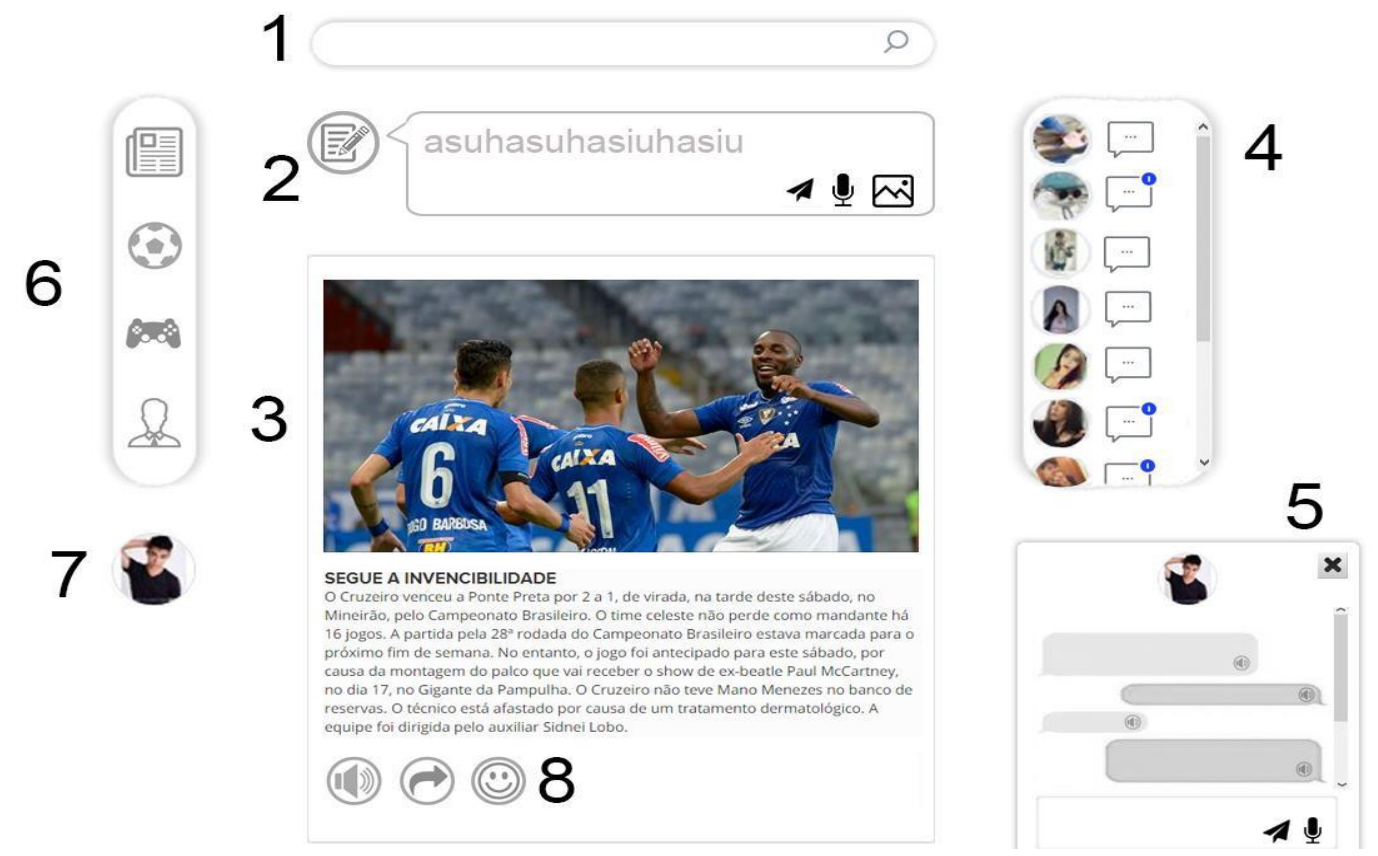

Figura 1 - Wireframe de alta fidelidade expandido com todas as funções sendo demonstradas ao mesmo tempo. 
Chegamos à conclusão, baseado no estudo, que um login utilizando apenas credenciais como habitualmente é feito, com um usuário e senha inseridos manualmente, seria ineficiente, ao perceber que houve uma grande dificuldade para que conseguissem realizar o acesso desta maneira, pois além de não lembrarem seus respectivos usuários e senhas, nenhum deles conseguiu concluir o cadastro e, partindo deste princípio, concluímos que a melhor maneira de conectar-se seria usando um tipo de login físico, como usando um pen drive, ou tirar a necessidade de um login. Também seria possível fazer utilizando reconhecimento de íris ou de digitais.

$\mathrm{O}$ acesso à página principal não requer login, permitindo que funções como o feed de notícias ainda seja acessado, mas se o mesmo for feito proporciona novas opções, assim como mostrado na figura 1.

As principais funções da rede são:

1. Barra de pesquisa no qual é possível pesquisar usando texto ou tags, palavras pré-definidas, selecionadas por meio de algoritmo, que serão exibidas abaixo da barra de pesquisa.

2. Caixa de Postagem, nessa parte é possível fazer uma publicação visível aos amigos, esta, podendo ser texto, foto ou áudio. Importante ressaltar que é possível deixar o conteúdo postado como público, podendo ser visto mesmo por pessoas que não estejam conectadas em seu perfil.

3. Área de foco onde podem ser exibidas postagens no geral, notícias sobre esportes, cotidiano, jogos ou publicações de amigos, todas as categorias exibindo informações na tela baseado nas tags contidas em cada um dos assuntos, cada publicação contém 3 ícones ao final dela, que serão melhor explicados no item 8 desta listagem.

4. Barra de amigos, como citado anteriormente, exibe suas amizades e um balão de conversa ao lado, para iniciar um chat.

5. Janela de chat para conversar com outros usuários.

6. Barra de foco, no qual pode ser escolhida a categoria das informações a serem exibidas na área de foco.

7. Imagem de perfil do usuário.

8. Conjunto de ícones para interação com a postagem sendo que o da esquerda reproduz um áudio que lê a sinopse da notícia, o botão do meio permite você compartilhar a notícia e o da direita, botão Interessante, para ser utilizado quando o usuário se interessar pela publicação, aumentando a relevância dela para outros usuários.

\subsection{Etapa de testes}

Devido a essas dificuldades e implicações no desenvolvimento foi decidido manter um padrão de login comum, com entrada manual, apenas para testes e durante as sessões o mesmo seria feito para eles, dessa forma conseguimos focar em outras prioridades que carecem de mais teste, como a função presente na área de foco da rede social, a função de Text to Speech (texto para voz, TTS).

Os testes foram conduzidos em duas etapas, sendo que nestas os avaliados utilizaram o protótipo da rede depois de uma breve explicação, e após avaliação e coleta de dados, utilizaram novamente a rede, agora com auxílio dos avaliadores. 


\begin{tabular}{|c|c|c|c|c|c|c|c|c|c|}
\hline \multirow{2}{*}{ Aluno } & \multirow{3}{*}{ Alfabetizado } & \multicolumn{6}{|c|}{ Entendimento com orientação inicial } & \multicolumn{3}{|c|}{$\begin{array}{l}\text { Entendimento após intervenção } \\
\text { do orientador }\end{array}$} \\
\cline { 3 - 11 } & & Feed & TTS & Chat & $\begin{array}{l}\text { Interface } \\
\text { Geral }\end{array}$ & Feed & TTS & Chat & $\begin{array}{l}\text { Interface } \\
\text { Geral }\end{array}$ \\
\hline $\mathbf{1}$ & Parcial & Bom & Médio & Bom & Bom & Bom & Médio & Bom & Bom \\
\hline $\mathbf{2}$ & Parcial & Médio & Médio & Ruim & Médio & Bom & Médio & Bom & Bom \\
\hline $\mathbf{3}$ & Sim & Bom & Bom & Bom & Bom & Bom & Bom & Bom & Bom \\
\hline $\mathbf{4}$ & Não & Ruim & Bom & Médio & Médio & Bom & Bom & Bom & Bom \\
\hline $\mathbf{5}$ & Não & Médio & Bom & Médio & Bom & Bom & Bom & Bom & Bom \\
\hline $\mathbf{6}$ & Não & Ruim & Bom & Médio & Médio & Médio & Bom & Médio & Médio \\
\hline $\mathbf{7}$ & Não & Médio & Bom & Médio & Médio & Bom & Bom & Bom & Bom \\
\hline
\end{tabular}

Tabela 1. Resultados dos testes de usabilidade do protótipo.

Os avaliadores classificaram o entendimento dos alunos no protótipo como bom, médio e ruim, sendo que:

- Bom: Conseguiu entender e utilizar a área avaliada da maneira esperada.

- Médio: Utilizou o sistema de maneira satisfatória, ainda que com dificuldade.

- Ruim: Não conseguiu utilizar a ferramenta ou utilizou a ferramenta de forma abaixo do esperado.

\subsubsection{Primeira etapa - Navegação na área de foco}

Em seguida a explicação inicial, alguns alunos ainda demonstraram dificuldades iniciais para entendimento do conceito e navegação do site, mas com o auxílio da ferramenta de leitura e alguns minutos de repetição a maioria conseguiu utilizar esta área do site de maneira razoável, e após a intervenção dos avaliadores quase todos navegaram de forma satisfatória, exemplificando a importância dos conceitos apresentados no modelo.

A ferramenta Text to Speech foi de suma importância para a compreensão desta área do site, a mesma ainda incentivou os alunos a tentarem praticar a leitura das publicações enquanto acompanhavam a voz da ferramenta, também pode-se observar a relevância desta ferramenta para o funcionamento do protótipo na utilização dela na barra do feed, onde, na troca de categoria das publicações, o TTS fala qual categoria foi selecionada, o que auxiliou na navegação.

O formato das notícias na página revelou-se satisfatória, as imagens destas mostraram-se fundamentais na compreensão e contextualização do conteúdo. Alguns dos usuários apresentaram leves dificuldades em assimilação das notícias com maior quantidade de palavras na primeira visualização.

\subsubsection{Segunda etapa - Troca de foto no perfil e utilização do chat}

Nesta fase dos testes, o login e senha criados com o nome dos alunos, apenas para testes e solicitado a eles que tentassem utilizá-las após a explicação, também foi explicado como trocar a foto e como acessar o chat.

Três deles não conseguiram digitar o nome sem auxílio dos avaliadores. A troca de fotos também teve de ser feita pelo avaliador, foram escolhidas fotos que eles desejaram, todos escolheram personagens fictícios. 
O chat, assim como o do Facebook, provou-se pouco intuitivo, o mesmo demandou um tempo muito maior de aprendizado do que o feed, por exemplo, o botão de leitura de mensagem com o TTS foi de extrema importância nesta fase, novamente considerando que a maioria dos avaliados é analfabeta.

Foi possível observar durante os testes, que o TTS aliada ao conceito de rede social tem um viés educativo, visto que a interação dos avaliados com o protótipo estimulou eles a tentarem melhorar suas habilidades de leitura e escrita, propondo um incentivo a mais no processo de alfabetização destes.

\section{Considerações finais}

É necessário ressaltar que o modelo deve ser próximo do ideal, mas no tempo do projeto foram criadas soluções para os problemas encontrados durante os testes. Não esperamos que o conceito deste projeto seja o melhor para todas as situações com qualquer tipo de pessoa, mas que demonstre soluções para todas dificuldades apresentadas pelos frequentadores do PROESP, demonstrando que é possível aliar redes sociais, inclusão e acessibilidade.

Visto isso, chegamos à conclusão de que o objetivo inicial do projeto foi cumprido. Durante os meses de confecção do estudo foi possível notar que é plausível aliar os conceitos citados acima, e por meio destes promover inclusão social e digital aos deficientes intelectuais.

Podemos ressaltar o surpreendente viés educativo que o projeto proporcionou, pois todos os avaliados durante as sessões de testes, apresentaram um maior interesse em aprimorar suas habilidades de leitura e escrita com o intermédio da ferramenta de leitura para isto.

Alguns dos elementos importantes do modelo não foram implementados no protótipo até o momento, como o login físico, publicações, pesquisa por tags, grupos de amizades, dentre outros. Planejamos futuramente adicionar estas funções ao site.

Um dos principais aspectos de grandes redes sociais virtuais é a inclusão social, este modelo, por si só não tem esta capacidade, sendo necessária a criação ou adaptação de uma rede com quantidade de usuários suficientes para que isto seja possível. Nossa expectativa é que conforme o passar dos anos uma das duas possibilidades sejam possíveis.

O conceito foi desenvolvido pensando nas principais dificuldades exemplificadas pelos alunos nos testes, e testada em ambiente controlado, desconsideramos no modelo e consequentemente na prototipagem determinadas questões finais do desenvolvimento de um site, numa aplicação fiel do modelo seria necessário ainda preocupar-se com estas, como questões relacionadas à segurança de dados, e detalhes menores da rede.

\section{Referencias}

AAIDD, Associação Americana sobre Deficiência Intelectual do Desenvolvimento. Definição disponível em: http://aaidd.org/intellectual-disability/definition. Adaptação e tradução via APAE-SP Disponível em: http://www.apaesp.org.br/pt-br/sobredeficienciaintelectual/Paginas/o-que-e.aspx. Último acesso: 01/12/2017.

ANDRADE, C.; FERRACI, F. A.; MORGADO, E. M.. Inclusão Digital na Terceira Idade. Anais do Congresso Semana da Educação Municipal de Bauru, Bauru: 
Secretaria de Educação de Bauru, 2016 v. 1, p. 102 - 104

Dados do Banco Mundial. (2011). Disponível em: http://siteresources.worldbank.org/DISABILITY/Resources/Regions/LAC/LACfacts heetEng.pdf. Último acesso: 01/12/2017.

FERREIRA, A. S., Elizângela P; Barros, R A.; Interfaces da informação e comunicação: possibilidades de inclusão digital do aluno com deficiência intelectual. V EPEAL pesquisa em educação: desenvolvimento, ética e responsabilidade social, 2010.

MARTELETO, Regina Maria. Análise de redes sociais - aplicação nos estudos de transferência da informação, 2001. Disponível em: http://www.scielo.br/pdf/ci/v30n1/a09v30n1.pdf.

OLIVEIRA, C. B. Mídia, cultura corporal e inclusão: conteúdos da educação física escolar. Revista Digital - Buenos Aires - Año 10 No. 77 - Octubre, 2004. Disponível em: http://www.efdeportes.com . Acesso em 4 dez. 2006.

ORTH, M. A.; MANGAN, P. K. V.; SARMENTO, D. F. Formação continuada de professores em informática na Educação Especial: análise de dissertações e teses. Rev. bras. educ. espec. 2011, vol.17, n.3, pp. 497-516. ISSN 1413-6538. Disponível em: http://dx.doi.org/10.1590/S1413-65382011000300010.

RECUERO, Raquel da Cunha. Redes Sociais na Internet: Considerações Iniciais. E Compós, v. 2, 2005. Disponível em: http://compos.org.br/seer/index.php/ecompos/article/view/144/145. Último acesso: 01/12/2017.

TAVARES, Mara R. N; Inclusão e uso das TIC na prática pedagógica: dificuldades e desafios, 2014; Disponível em: http://www.lume.ufrgs.br/handle/10183/117558.

UNESCO : TIC na educação do Brasil. Disponível em: http://www.unesco.org/new/pt/brasilia/communication-and-information/access-toknowledge/ict-in-education/. Último acesso: 01/12/2017

VIANNA, P. B. M. Formação de professores/mediadores para o uso das TIC: elementos teóricos e práticos trabalhados em uma pesquisa-ação. UNIRevista, São Leopoldo, v.1, n.2, abril, p.1-12, 2006.

W3C Brasil, Cartilha de Acessibilidade na Web. Disponível em: http://www.w3c.br/pub/Materiais/PublicacoesW3C/cartilha-w3cbr-acessibilidadeweb-fasciculo-I.html. Último Acesso: 01/06/2018.

Projeto Acesso para Todos. Disponível em: https://www.acessoparatodos.com.br/. Ultimo Acesso: 01/06/2018.

Todos Nós - Unicamp Acessível. Disponível em: http://eurydice.nied.unicamp.br/portais/todosnos/nied/todosnos.html. Ultimo Acesso: 01/06/2018. 